\title{
BMJ Open Validation of the Compassion Fatigue Short Scale among Chinese medical workers and firefighters: a cross-sectional study
}

\author{
Binghai Sun, ${ }^{1}$ Mengna Hu, ${ }^{1}$ Shitian $\mathrm{Yu},{ }^{1}$ Yiru Jiang, ${ }^{2}$ Baona Lou ${ }^{3}$
}

To cite: Sun B, Hu M, Yu S, et al. Validation of the Compassion Fatigue Short Scale among Chinese medical workers and firefighters: a cross-sectional study. BMJ Open 2016;6: e011279. doi:10.1136/ bmjopen-2016-011279

- Prepublication history for this paper is available online. To view these files please visit the journal online (http://dx.doi.org/10.1136/ bmjopen-2016-011279)

Received 25 January 2016 Revised 30 May 2016 Accepted 3 June 2016

CrossMark

\begin{abstract}
${ }^{1}$ College of Teachers Education, Zhejiang Normal University, Jinhua, China ${ }^{2}$ Top Vocational College of Information Technology, Suzhou, China

${ }^{3}$ Shangyu Foreign Language School, Shaoxing, China
\end{abstract}

Correspondence to Binghai Sun; bhsun0579@sina.com

\section{ABSTRACT}

Objectives: To examine the psychometric properties of the Chinese version of the C-Compassion Fatigue (CF)-Short Scale among 4 independent samples of Chinese emergency workers (medical workers and firefighters).

Design: Cross-sectional.

Setting: 6 hospitals in Zhejiang Province and 12 fire stations in Shanghai.

Participants: Emergency workers (medical and firefighters) were consecutively recruited and divided into 4 groups: the MW1 group (medical workers, $n=167$ ), the FF1 group (firefighters, $n=157$ ), the MW2 group (medical workers, $\mathrm{n}=265$ ) and the FF2 group (firefighters, $n=231$ ).

Interventions: All patients completed the C-CF-Short Scale to identify factors associated with compassion fatigue. The MW1 and FF1 groups were used for the exploratory analyses. The MW2 and FF2 groups were used for the confirmatory factor analyses.

Primary and secondary outcome measures: Factor loading, correlations with previously validated questionnaires (the Ego-Resiliency Scale, the Social Support Questionnaire and the Job Pressure Scale) and Cronbach's $\alpha$ coefficient were tested for each factor.

Results: The C-CF-Short Scale demonstrated excellent construct validity and good internal consistency. Specifically, the results of exploratory factor analyses in the MW1 and FF1 groups showed that secondary trauma and job burnout were associated with compassion fatigue in these emergency workers. The confirmatory factor analyses in the MW2 and FF2 groups indicated that all the fit indices of the 2-factor model were satisfactory. Finally, the Cronbach's $\alpha$ coefficient of each factor was excellent.

Conclusions: The findings suggest that the C-CFShort Scale has good psychometric properties and can be applied to study Chinese emergency workers.

\section{INTRODUCTION}

There are $\sim 125400$ fires and 210800 traffic accidents that affect about two million Chinese people each year. ${ }^{1}$ Many people
Strengths and limitations of this study

- This study included a large number of participants.

- The Chinese version of the C-Compassion Fatigue (CF)-Short Scale was validated against three questionnaires that were previously validated in a Chinese population.

- The sample was from a single Chinese region and results may be slightly different for regions that have different proportions of ethnic groups.

- Only medical workers and firefighters were included.

support these victims, including social workers, medical workers, firefighters and counsellors. ${ }^{1}$ Emergency workers suffer from enormous working pressure as well as tremendous psychological burden, and are at high risk for serious mental health issues. Indeed, they are likely to develop 'compassion fatigue' $(\mathrm{CF})$, which is helpers' negative mental health outcomes deriving from the traumatic event itself and from helping the victims. ${ }^{2}$ There are similarities in the indirect occurrence and clinical symptoms between $\mathrm{CF}$, secondary traumatic stress and vicarious trauma, ${ }^{3-6}$ but the prominent symptom of $\mathrm{CF}$ is a reduced empathy for victims.

On the basis of his extensive clinical experience, Figley ${ }^{2} 7$ proposed a two-factor model and developed a scale (the Compassion Fatigue Self-Test, CFST) that consists of two subscales (CF and burnout). Later, Gentry et al suggested that CF comprised secondary traumatic stress/CF and burnout. They removed some items from the CFST and developed the Compassion Fatigue Scale-Revised (CFS-R), which has been used in many previous studies. ${ }^{9}{ }^{10}$ Using a sample of social workers who cared for victims of the 9/11 attack in New York City, Boscarino et $a l^{11}$ assessed the psychometric properties of the CFS-R and revised the scale again to 
develop the Compassion Fatigue (CF)-Short Scale, which consists of two subscales: secondary trauma (ST) and job burnout (JB). Adams $e t a l^{12}$ examined the reliability and validity of the CF-Short Scale, and the results showed that the scale had excellent reliability, construct validity and predictive validity.

Many authors ${ }^{4}{ }^{13-15}$ conducted studies of CF among medical workers and firefighters, and they demonstrated that these two groups of emergency workers were at high risk of $\mathrm{CF}$ and other mental health issues. Meanwhile, some surveys of helpers in China showed that these two groups were at high risk for mental health problems and that their general mental health status was lower than that in the general population. ${ }^{16-18}$ Indeed, these two groups of emergency workers are often at the frontline in cases of disaster and accidents. In addition, a meta-analysis showed that rescue workers felt less supported by their social network in times of crisis. ${ }^{19}$ Indeed, highly stressful events may lead to relocation, job loss, bereavement, divorce and perturbations of social relationships, decreasing the well-being of the rescue workers. ${ }^{19}$ Individuals receiving proper social support have a lower incidence of $\mathrm{CF}^{20}$ but some studies showed that $\mathrm{CF}$ is negatively associated with ego-resilience. Indeed, individuals with higher ego-resilience could better suppress or overcome the occurrence of $\mathrm{CF}^{21}$

Very little work has been carried out to examine $\mathrm{CF}$ among Chinese people. Moreover, there is a lack of $\mathrm{CF}$ assessment instruments in China. Although the CF-Short Scale has been applied in several studies of CF among emergency workers in European and American settings, it has not been used in Chinese emergency workers. To fill this gap, this study aimed to explore the structure of $\mathrm{CF}$ and examine the psychometric properties of the Chinese version of the CF-Short Scale among medical workers and firefighters. In accordance with prior studies, we hypothesised that $\mathrm{CF}$ includes two factors in Chinese emergency workers: ST and JB. We also hypothesised that the Chinese version has good internal consistency reliability.

\section{MATERIALS AND METHODS \\ Study design}

This was a prospective survey study carried out among medical workers from six hospitals in the Zhejiang Province and firefighters from 12 fire stations in Shanghai. Surveys were obtained between October 2011 and January 2012. The study was approved by the Ethical Committee of the Teachers' Education College of Zhejiang Normal University. Written informed consent was obtained from each participant.

\section{Participants}

Participants were recruited using convenience sampling and included 432 medical workers recruited from six hospitals in Zhejiang Province and 388 firefighters from 12 fire stations in Shanghai.

\section{Questionnaires}

Five hundred questionnaires were handed out in the six hospitals and 450 were recovered (recovery rate of $90 \%$ ). A questionnaire was considered invalid if $>10 \%$ of the questions were unanswered, leaving 432 usable questionnaires (effective rate of $86.4 \%$ ).

Four hundred and fifty questionnaires were handed out in fire stations in Shanghai and 400 were recovered (recovery rate of $88.9 \%$ ). After excluding invalid questionnaires, there were 388 effective questionnaires (effective rate of $86.2 \%$ ).

\section{Grouping}

Each group was randomly separated into two validation subgroups: the medical workers were divided into the MW1 ( $n=167)$ and the MW2 ( $n=265)$ groups; and the firefighters were divided into the FF1 $(n=157)$ and FF2 $(n=231)$ groups. Randomisation was carried out using a random number table.

\section{Traumatic events}

Workers who had experienced traumatic events were those who were under the threat of serious injury or death in the line of duty, those who worked in settings involving multiple deaths and injuries, those who had close contacts with burnt or mutilated victims, and those who were involved in prolonged extrication of trapped victims with life-threatening injuries. ${ }^{19}$ These events were assessed by self-reporting. The police records of the events were reviewed to confirm the self-reported events.

\section{Chinese version of the CF-Short Scale}

The CF-Short Scale is a 13-item self-reported questionnaire that consists of two subscales: (1) a 5-item ST scale, and (2) an 8-item JB scale. ${ }^{12}$ Participants are asked to rate the frequency of how often each item applies to themselves on a 10-point Likert scale ranging from 1 (rarely/never) to 10 (very often). According to Adams et $a l,{ }^{12}$ the Cronbach's $\alpha$ coefficients of the subscales range from 0.80 to 0.90 , demonstrating adequate internal reliability.

For this study, the CF-Short Scale was first translated into Mandarin Chinese by a professional translator and then back translated into English by another. Discrepancies between the English and Chinese versions were evaluated by an expert panel that included psychologists and professional translators. Discrepancies were gradually reduced through an iterative review process.

\section{Ego-Resiliency Scale}

Ego resiliency is defined as the ability to adapt one's level of control temporarily up or down as circumstances dictate. ${ }^{22}$ It is often measured using the Ego-Resiliency Scale (ERS). The ERS was originally developed by Block and Kremen. ${ }^{23}$ It has 14 items rated on a four-point Likert-type scale ranging from 1 (strongly disagree) to 4 (strongly agree). According to Block and Kremen, ${ }^{23}$ the internal consistency reliability is $0.76 . \mathrm{Li}$ and Zhang ${ }^{24}$ 
established that the Chinese version of the ERS had a good split-half reliability $(\alpha=0.75)$, good test-retest reliability $(\mathrm{r}=0.71)$ and good internal consistency reliability $(\alpha=0.73)$. In the current study, the ERS was used in the MW2 and FF2 groups. The internal consistency coefficient of the C-ERS was 0.81 for the MW2 group and 0.84 for the FF2 group.

\section{Social Support Questionnaire}

Social support is often divided into two categories: received/enacted social support and perceived social support. $\mathrm{Xiao}^{25}$ proposed that the extent to which support is used should be incorporated into the definition of social support. $\mathrm{Xiao}^{25}$ developed the Social Support Questionnaire (SSQ). The SSQ has three dimensions: objective support, subjective support and degree of support usage. Since 1986, the SSQ has been widely used in the Chinese society and translated into Japanese in the setting of an international collaborative project. According to Xiao, ${ }^{25}$ the Cronbach's $\alpha$ coefficient of this scale ranges from 0.89 to 0.94 . In this study, the SSQ was used in the MW2 and FF2 groups. The internal consistency coefficients were 0.75 for the MW2 group and 0.85 for the FF2 group.

\section{Job Pressure Scale}

Job pressure is defined as the results of the interactions between individuals and environments and was measured using the Job Pressure Scale (JPS). The 18-item JPS was developed by $\mathrm{Li}$ and $\mathrm{Zhang}^{24}$ and assesses four factors: work-related pressure, organisational management, career development and interpersonal relationships. ${ }^{24}$ Responses range from 1 (strongly disagree) to 5 (strongly agree). The JPS has good reliability, ranging from 0.80 to 0.85 . In this study, the scale was used in the NW2 and FF2 groups. The internal consistency coefficients of the JPS were 0.86 for the MW2 group and 0.83 for the FF2 group.

\section{Statistical analysis}

SPSS V.16.0 (exploratory analyses; IBM, Armonk, New York, USA) and Lisrel V.8.7 (confirmatory analyses; Scientific Software International, Skokie, Illinois, USA) were used for analyses. Continuous variables are presented as mean $\pm \mathrm{SD}$ and were analysed using the Student's t-test. Categorical variables are presented as frequencies and were analysed using the $\chi^{2}$ test. The factor structure of the C-CF-Short Scale was examined using exploratory and confirmatory factor analyses. First, an exploratory factor analysis was carried out with the MW1 group $(\mathrm{n}=167)$, using principal component analysis as the extraction method. The MW1 and FF1 groups were used for item and exploratory factor analyses. Next, the MW2 and FF2 groups were used for confirmatory factor analyses. Finally, reliability analysis was performed in all four groups. Two-sided $\mathrm{p}<0.05$ were considered statistically significant.
Owing to the small proportion of missing data $(<1.5 \%$ for all variables), the missing data estimation used in this study was based on the listwise deletion method. ${ }^{26} 27$ The Kaiser-Meyer- Olkin (KMO) value was 0.849, suggesting that factor analysis should be performed. Oblique rotation was used for the principal component analysis, and scree plot was used to extract the factors. Structural equation modelling was used to determine the correlations between the C-CF-Short Subscales and other questionnaires.

\section{RESULTS}

\section{Characteristics of the participants}

Table 1 presents the characteristics of the MW and FF groups. There were no differences between each of the pairs of subgroups (MW1 vs MW2; FF1 vs FF2).

\begin{tabular}{|c|c|c|c|}
\hline Medical workers & $\begin{array}{l}\text { MW1 } \\
n=167\end{array}$ & $\begin{array}{l}\text { MW2 } \\
n=265\end{array}$ & p Value \\
\hline \multicolumn{4}{|l|}{ Position } \\
\hline Doctor & 79 & 103 & \multirow[t]{3}{*}{0.197} \\
\hline Nurse & 53 & 103 & \\
\hline Other & 35 & 59 & \\
\hline \multicolumn{4}{|l|}{ Gender } \\
\hline Male & 53 & 72 & \multirow[t]{2}{*}{0.308} \\
\hline Female & 114 & 193 & \\
\hline \multicolumn{4}{|l|}{ Age (years) } \\
\hline Mean \pm SD & $31.1 \pm 9.0$ & $30.9 \pm 8.7$ & 0.854 \\
\hline \multicolumn{4}{|c|}{ Work experience (years) } \\
\hline Mean $\pm S D$ & $10.4 \pm 9.6$ & $10.0 \pm 8.9$ & 0.683 \\
\hline \multicolumn{4}{|l|}{ Marital status } \\
\hline Married & 95 & 165 & \multirow[t]{2}{*}{0.266} \\
\hline Not married & 72 & 100 & \\
\hline \multicolumn{4}{|c|}{ Personal trauma history } \\
\hline Yes & 111 & 160 & \multirow[t]{2}{*}{0.108} \\
\hline No & 52 & 105 & \\
\hline \multicolumn{4}{|l|}{ Firefighters } \\
\hline & FF1 & \multirow{2}{*}{\multicolumn{2}{|c|}{$\begin{array}{l}\text { FF2 } \\
n=231\end{array}$}} \\
\hline & $n=157$ & & \\
\hline \multicolumn{4}{|l|}{ Gender } \\
\hline Male & 145 & 219 & \multirow[t]{2}{*}{0.326} \\
\hline Unreported & 12 & 12 & \\
\hline \multicolumn{4}{|l|}{ Age (years) } \\
\hline Mean $\pm S D$ & $23.2 \pm 3.6$ & $22.8 \pm 3.2$ & 0.242 \\
\hline \multicolumn{4}{|c|}{ Work experience (years) } \\
\hline Mean $\pm S D$ & $4.5 \pm 3.1$ & $4.2 \pm 2.7$ & 0.248 \\
\hline \multicolumn{4}{|l|}{ Marital status } \\
\hline Married & 25 & 34 & \multirow[t]{2}{*}{0.746} \\
\hline Not married & 132 & 197 & \\
\hline \multicolumn{4}{|c|}{ Regular participation in emergency rescue } \\
\hline Yes & 105 & 147 & \multirow[t]{2}{*}{0.525} \\
\hline No & 49 & 79 & \\
\hline \multicolumn{4}{|c|}{ Personal trauma history } \\
\hline Yes & 90 & 123 & \multirow[t]{2}{*}{0.428} \\
\hline No & 67 & 108 & \\
\hline
\end{tabular}




\section{Validity of the C-CF-Short Scale}

The factor structure of the C-CF-Short Scale was examined using exploratory and confirmatory factor analyses. First, an exploratory factor analysis was carried out with the MW1 group ( $n=167)$. Results from the Bartlett's test of sphericity $(\mathrm{p}<0.001)$ and the Kaiser-Meyer-Olkin measure of sampling adequacy (0.849) suggested that the correlation matrix was appropriate for factor analysis. Thus, a principal component analysis was carried out using the oblique rotation. Two factors with eigenvalues $>1$ emerged, and an examination of the scree plot (figure 1A) also suggested the same two primary factors. These two factors explained $52.0 \%$ of the variance. Items 1, 2, 4, 6, 7, 9, 11 and 13 loaded strongly on factor $1(\mathrm{JB})$, and items 3, 5, 8, 10 and 12 loaded strongly on factor 2 (ST). Therefore, the results revealed a twofactor solution among medical workers.

Similarly, another exploratory factor analysis was carried out with the FF1 group $(n=157)$. Results from the Bartlett's test of sphericity $(p<0.001)$ and the Kaiser-Meyer-Olkin measure of sampling adequacy (0.830) suggested that the correlation matrix was appropriate for factor analysis. Therefore, a principal component analysis was carried out using the oblique rotation.
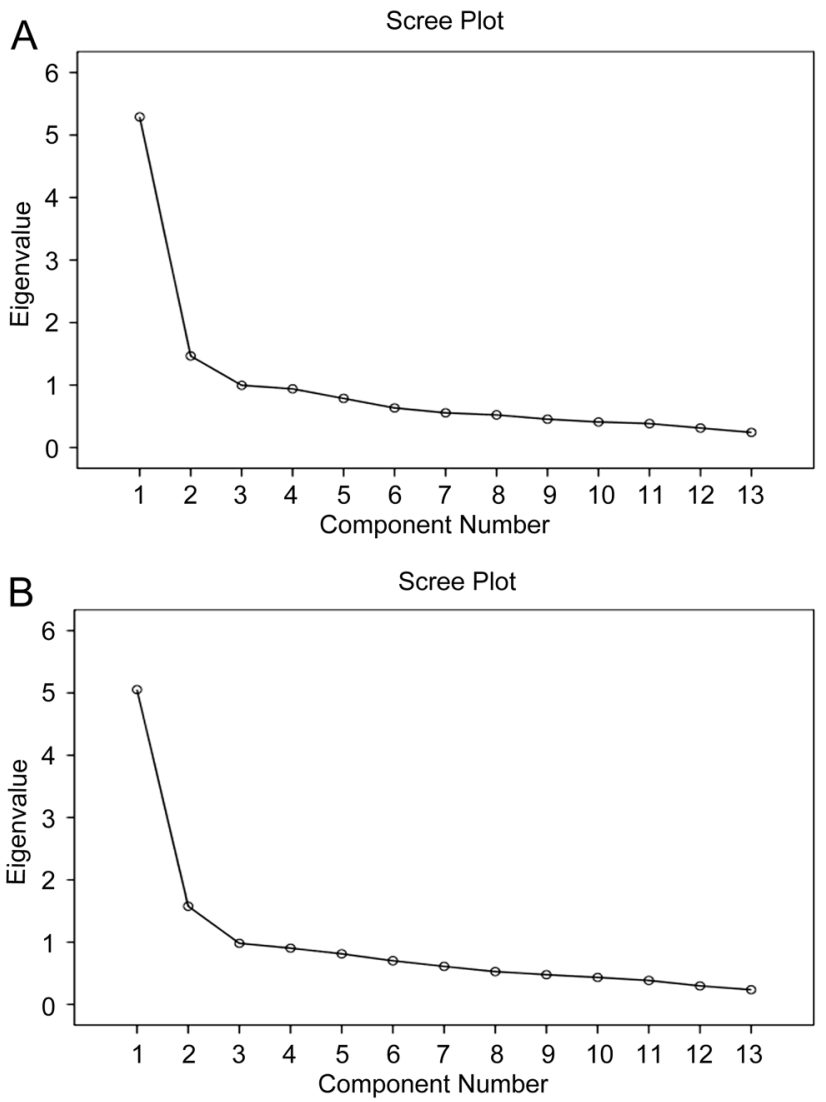

Figure 1 (A) Scree plot for the C-CF-Short Scale (MW1 group, $n=167$ ). (B) Scree plot for the C-CF-Short Scale (FF1 group, $n=157)$. C-CF-Short Scale, C-Compassion Fatigue-Short Scale; FF1, firefighter group 1; MW1, medical workers group 1.
Two factors with eigenvalues $>1$ emerged, and they explained $51.0 \%$ of the variance. An examination of the scree plot (figure 1B) also suggested two primary factors. Again, items 1, 2, 4, 6, 7, 9, 11 and 13 loaded strongly on actor $1(\mathrm{JB})$, and items $3,5,8,10$ and 12 loaded strongly on factor 2 (ST). Therefore, the results revealed a two-factor solution among firefighters as well.

Taken together, the two exploratory factor analyses using the MW1 and FF1 groups indicated that the C-CF-Short Scale was composed of two factors (JB and ST). Table 2 presents the factor loadings of all items (all >0.54) and the variances explained by the two factors in each sample. Overall, the factor structure of the scale was the same across the two samples.

To cross-validate the two-factor model, confirmatory factor analyses were performed with the remaining two independent groups (MW2, n=265; FF2, n=231). A variety of indices $\left(\chi^{2} / \mathrm{df}\right.$, comparative fit index (CFI), root mean square error of approximation (RMSEA) and standardised root mean square residual (SRMR)) were

Table 2 Items and factor loadings (MW1 group, $\mathrm{n}=167$; FF1 group, $n=157$ )

\section{Item (\% variance explained)}

Factor loadings

Factor 1: job burnout (29.7-27.7\%)

9. I have felt depressed because of my work.

13. I have a sense of worthlessness, disillusionment or resentment associated with my work.

1. I have felt trapped by my work. MW1 FF1

11. I feel I am unsuccessful at separating work from my personal life.

6. I have felt a sense of hopelessness associated with working with clients/ patients.

4. I feel that I am a 'failure' in my work. $0.80 \quad 0.66$ $0.77 \quad 0.64$

2. I have thoughts that I am not succeeding in achieving my life goals.

7. I have frequently felt weak, tired or rundown because of my work as a caregiver.

Factor 2: secondary stress (22.3-23.3\%)

5. I experience troubling dreams similar to $\quad 0.75 \quad 0.71$ those of a client of mine.

10. I have suddenly and involuntarily recalled a frightening experience while working with a client/patient.

12. I am losing sleep over a client's $\quad 0.73 \quad 0.76$ traumatic experiences.

3. I have had flashbacks connected to my $\quad 0.72 \quad 0.67$ clients.

8. I have experienced intrusive thoughts $\quad 0.59 \quad 0.54$ after working with an especially difficult client/patient.

FF1, firefighters group 1; MW1, medical workers group 1. 
Table 3 Correlations between the C-CF-Short Subscales and other questionnaires (MW2 group, n=265; FF2 group, $n=231$ ), according to the structural equation model

\begin{tabular}{|c|c|c|c|c|c|c|c|c|}
\hline & \multicolumn{4}{|l|}{ MW2 } & \multicolumn{4}{|l|}{ FF2 } \\
\hline & Mean \pm SD & 1 & 2 & 3 & Mean \pm SD & 1 & 2 & 3 \\
\hline Secondary stress & $16.6 \pm 8.7$ & - & & & $17.1 \pm 9.3$ & - & & \\
\hline Job burnout & $32.0 \pm 14.9$ & $0.73^{\star \star \star}$ & - & & $28.3 \pm 14.3$ & $0.87^{\star * \star}$ & - & \\
\hline Compassion fatigue & $48.6 \pm 21.6$ & $0.86^{\star \star \star}$ & $0.95^{\star \star \star}$ & - & $45.4 \pm 22.9$ & $0.95^{\star \star \star}$ & $0.98^{\star \star \star}$ & - \\
\hline Ego-resiliency & $35.8 \pm 6.4$ & -0.06 & $-0.26^{\star * *}$ & $-0.19^{\star \star}$ & $40.9 \pm 6.6$ & $-0.22^{\star \star}$ & $-0.25^{\star \star \star}$ & $-0.21^{\star \star \star}$ \\
\hline Social support & $39.5 \pm 7.3$ & -0.01 & -0.14 & -0.07 & $34.7 \pm 8.5$ & $-0.34^{\star \star *}$ & $-0.35^{\star \star \star}$ & $-0.31^{\star * *}$ \\
\hline Work stress & $55.7 \pm 11.8$ & $0.28^{\star \star \star}$ & $0.58^{\star \star \star}$ & $0.45^{\star \star \star}$ & $61.3 \pm 10.1$ & $-0.25^{\star \star \star}$ & $-0.18^{\star \star}$ & $-0.23^{\star \star \star}$ \\
\hline
\end{tabular}

used to assess the model fit. ${ }^{28}$ In general, the CFI value of $\geq 0.90$ is considered evidence of a good fit, ${ }^{29}$ as are the RMSEA and SRMR values of $\leq 0.08$ or lower. $^{28}$ The results suggested that the two-factor model fitted the two samples reasonably well, with a similar goodness of fit across the MW2 group $\left(\chi^{2}=147.34, \mathrm{df}=61, \mathrm{p}<0.001\right.$; $\mathrm{CFI}=0.98$; SRMR $=0.06$; RMSEA $=0.07)$ and the FF2 group $\left(\chi^{2}=131.42, \quad \mathrm{df}=54, \quad \mathrm{p}<0.001 ; \quad \mathrm{CFI}=0.99 ; \quad \mathrm{SRMR}=0.04 ;\right.$ RMSEA $=0.08)$.

The MW2 and FF2 groups were used to evaluate the correlation of each subscale with the criterion variables (table 3). The Pearson correlation was used for correlation analysis. As shown in table 3, CF was positively correlated with ST and JB, and ST was positively correlated with JB. JB and CF were negatively correlated with ego resiliency. Social support was negatively associated with CF. Finally, work stress was positively correlated with ST, JB and CF (table 3).

A variance analysis was carried out to test whether the C-CF-Short scores differed as a function of years of working experience in the MW2 group. In China, 3 years of working experience generally suggests that the worker has completed the training period and has some basic expertise and knowledge in his field, and 14 years of working experience generally suggests that the worker is skilled. As shown in table 4, the working experience of medical workers was associated with ST, JB and overall CF. According to multiple comparisons, medical workers with a working experience $>14$ years and those with an experience of 3-14 years showed a higher incidence of ST, JB and overall CF compared with participants with a working experience $<3$ years.

Independent-samples t-tests were performed to test whether the C-CF-Short scores were associated with the frequency of participation in rescue in the FF2 group. Firefighters who participated often in emergency rescue showed higher incidence of JB compared with those who seldom participated in emergency rescue (29.6 \pm 14.5 vs $25.2 \pm 13.8, \mathrm{p}=0.03$ ). Regular participation was defined as $>5$ times every year, and low participation was defined as $<5$ times every year. There were no differences in ST (17.6 \pm 9.5 vs $15.8 \pm 8.8, \mathrm{p}=0.175)$ and $\mathrm{CF}(47.2$ \pm 23.0 vs $41.1 \pm 22.3, \mathrm{p}=0.054)$.

Moreover, whether CF differed as a function of personal trauma history was examined. Personal trauma history was defined as a history of serious disease, car accident, suicide of a close relative, death of a close relative and being injured in natural or man-made disasters. Medical workers with a personal trauma history had a higher incidence of ST (17.8 \pm 9.0 vs $14.8 \pm 7.9, \mathrm{p}=0.007)$, JB $(34.0 \pm 14.3$ vs $28.9 \pm 15.2, \quad \mathrm{p}=0.006)$ and overall $\mathrm{CF}$ (51.7 \pm 21.7 vs $43.7 \pm 20.8, \mathrm{p}=0.003)$ compared with those without a personal trauma history. There were no significant differences in total and subscale scores between firefighters with and without a personal trauma history: ST $(17.8 \pm 9.4$ vs $16.4 \pm 9.1, \quad \mathrm{p}=0.272)$, JB $(29.1 \pm 15.1$ vs $27.32 \pm 13.5, \mathrm{p}=0.322)$ and overall $\mathrm{CF}(46.9 \pm 23.6$ vs 43.7 $\pm 21.9, \mathrm{p}=0.286$ ).

Table 4 Association of the C-CF-Short Scale with working experience in the MW2 group

\begin{tabular}{|c|c|c|c|c|c|}
\hline & \multicolumn{5}{|l|}{ MW2 (n=265) } \\
\hline & $\begin{array}{l}1 \\
<3 \text { years }(n=85) \\
\text { Mean } \pm S D\end{array}$ & $\begin{array}{l}2 \\
3-14 \text { years }(n=92) \\
\text { Mean } \pm S D\end{array}$ & $\begin{array}{l}3 \\
>14 \text { years }(n=88) \\
\text { Mean } \pm \text { SD }\end{array}$ & p Value & Tukey's post hoc test \\
\hline $\begin{array}{l}\text { Secondary stress } \\
\text { Job burnout } \\
\text { Compassion fatigue }\end{array}$ & $\begin{array}{l}14.0 \pm 8.1 \\
27.7 \pm 11.4 \\
41.6 \pm 17.6\end{array}$ & $\begin{array}{l}17.1 \pm 9.5 \\
35.2 \pm 16.2 \\
52.3 \pm 23.8\end{array}$ & $\begin{array}{l}18.5 \pm 7.8 \\
32.8 \pm 15.5 \\
51.4 \pm 21.4\end{array}$ & $\begin{array}{l}0.002^{\star \star} \\
0.003^{\star \star} \\
0.001^{\star \star}\end{array}$ & $\begin{array}{l}2,3>1^{\#} \\
2,3>1^{\#} \\
2,3>1^{\#}\end{array}$ \\
\hline
\end{tabular}




\section{Reliability of the C-CF-Short Scale}

The internal reliability of the C-CF-Short Scale for each group was computed. All three subscales of the C-CF-Short Scale demonstrated satisfactory internal consistency reliabilities in all four groups (MW1: ST $=0.79$, $\mathrm{JB}=0.85, \mathrm{CF}=0.87$; MW2: $\mathrm{ST}=0.83, \mathrm{JB}=0.87, \mathrm{CF}=0.90 ; \mathrm{FF} 1$ : $\mathrm{ST}=0.79, \quad \mathrm{JB}=0.83, \quad \mathrm{CF}=0.87 ; \quad \mathrm{FF} 2 ： \mathrm{ST}=0.90, \quad \mathrm{JB}=0.92$ ， $\mathrm{CF}=0.95)$.

\section{DISCUSSION}

The C-CF-Short Scale is a good tool for assessing CF, but it is not validated in a Chinese population. Therefore, this study aimed to examine the psychometric properties of the Chinese version of the C-CF-Short Scale in four independent samples of Chinese emergency workers (medical workers and firefighters). Results showed that the C-CF-Short Scale demonstrated excellent construct validity and good internal consistency. Specifically, the results of the two exploratory factor analyses in the MW1 and FF1 groups showed that ST and JB were associated with $\mathrm{CF}$ in these workers. The results of the confirmatory factor analyses with the MW2 and FF2 groups indicated that all the fit indices of the two-factor model were satisfactory. Finally, the Cronbach's $\alpha$ coefficient of each factor was excellent.

The results of the two exploratory factor analyses (MW1 and FF1 groups) showed that the C-CF-Short Scale was composed of two factors (JB and ST), which was in line with the two subscales of the original CF-Short Scale. ${ }^{12}$ The results of the confirmatory factor analyses showed that all fit indices of the two-factor model were satisfactory, suggesting excellent construct and cross-validation. The Cronbach's $\alpha$ coefficients also demonstrated excellent internal reliability among the four groups: the internal consistency coefficients of the ST ranged subscale from 0.79 to 0.90 , while those of the JB subscale ranged from 0.83 to 0.92 , and those of the $\mathrm{CF}$ total scale ranged from 0.87 to 0.95 . The excellent reliability of the subscales and total scale were also in accordance with the original CF-Short Scale. ${ }^{12}$ Therefore, the C-CF-Short Scale can be applied to study Chinese emergency workers, or at least in medical workers and firefighters.

This study has at least three specific implications for emergency workers. First, medical workers whose working experience was $>14$ and 3-14 years scored higher on ST, JB and CF than those with a working experience $<3$ years. The reason why the experienced medical workers may experience more ST is that they are more exposed to disease or traumatic events than inexperienced workers. In addition, indirect trauma exposure may negatively affect the health and functioning status of medical workers. ${ }^{30}$ With increasing working years, medical workers will acquire more emotional memory and experience. Therefore, they can better understand the change of patients' mental emotion. Medical workers tend to offer help to patients and it is the reason why they are prone to JB. In addition, a previous study showed that $\mathrm{CF}$ was associated with the workload of nurses. ${ }^{31}$ This parameter was not assessed in this study, but will be an interesting point to study in the future.

This study showed that firefighters who often participated in emergency rescue showed a higher incidence of JB compared with those who did not. This is because the rescue operation requires a great deal of energy, as well as reduced vacation time. In addition, with the expansion of their work scope along with the increase of rescue missions, experienced firefighters deal with different kinds of traumatic experiences such as traffic accidents, building collapse, natural disasters, etc. JB may contribute to the subsequent depletion of their internal resources, decreased performance and negative health outcomes such as psychological distress and somatic complaints.

Third, there were significant differences in ST, JB and overall CF between medical workers with and without a personal trauma history, whereas no statistically significant difference was found in firefighters. It appears that personal trauma may not necessarily induce CF. Indeed, Rudolph et $a l^{10}$ argue that personal trauma history may elicit both induction and inhabitation for CF. On the one hand, people who have a personal trauma history may frequently recall the unpleasant experience, which may cause CF. On the other hand, they may also learn some coping strategies after being exposed to traumatic events. Consequently, when facing similar situations in the future, they can deal with them and seldom have CF. Future research should examine why personal trauma history did not matter for CF among firefighters. Nevertheless, our findings suggest that intervention and counselling services should be provided to Chinese emergency workers, especially to those with a personal trauma history and substantial emergency working experience.

This study is not without limitations. The sample was from a single Chinese region and results may be slightly different among regions that include different proportions of ethnic groups. In addition, only medical workers and firefighters were included and it would be interesting to assess the C-CF-Short Scale in other professions such as counsellors and the military. Even if this study validated the Chinese version of the C-CF-Short Scale, additional studies are necessary to examine its value in the Chinese population.

In conclusion, the findings suggest that the C-CFShort Scale has good psychometric properties and can be applied to study Chinese emergency workers.

Acknowledgements The authors acknowledge the invaluable participation of the study participants.

Contributors BS is the guarantor for the integrity of the data on which the article is based. He conceived of the study, participated in data collection, data analysis, data interpretation and wrote the manuscript. MH, SY, YJ and BL carried out the data collection and analysis, and provided the critical revision. All authors read and approved the final manuscript. 
Funding This study was supported by the National Social Science Fund (CBA120107).

Competing interests None declared.

Patient consent Obtained.

Ethics approval The Ethical Committee of the Teachers' Education College of Zhejiang Normal University.

Provenance and peer review Not commissioned; externally peer reviewed.

Data sharing statement No additional data are available.

Open Access This is an Open Access article distributed in accordance with the Creative Commons Attribution Non Commercial (CC BY-NC 4.0) license, which permits others to distribute, remix, adapt, build upon this work noncommercially, and license their derivative works on different terms, provided the original work is properly cited and the use is non-commercial. See: http:// creativecommons.org/licenses/by-nc/4.0/

\section{REFERENCES}

1. Li XK. Vicarious traumatization and social relief work among rescue workers in catastrophic events. China Public Security (Academy Edition) 2008;12:75-8.

2. Figley CR. Compassion fatigue as secondary traumatic stress disorder: an overview. In: Figley CR, ed. Compassion fatigue: coping with secondary traumatic stress disorder in those who treat the traumatized. New York: Brunner-Routledge, 1995:1-20.

3. Bride BE, Radey M, Figley CR. Measuring compassion fatigue. Clin Soc Work J 2007;35:155-63.

4. Beck CT. Secondary traumatic stress in nurses: a systematic review. Arch Psychiatr Nurs 2011;25:1-10.

5. Devilly GJ, Wright R, Varker T. Vicarious trauma, secondary traumatic stress or simply burnout? Effect of trauma therapy on mental health professionals. Aust N Z J Psychiatry 2009;43:373-85.

6. Stewart DW. Casualties of war: compassion fatigue and health care providers. Medsurg Nurs 2009;18:91-4.

7. Figley CR. Compassion fatigue: psychotherapists' chronic lack of self care. J Clin Psychol 2002;58:1433-41.

8. Gentry JE, Baranowsky AB, Dunning K. ARP: the accelerated recovery program (ARP) for compassion fatigue. In: Figley $\mathrm{CR}$, ed. Treating compassion fatigue. New York: Brunner-Rutledge, 2002: 123-37.

9. Jenkins SR, Baird S. Secondary traumatic stress and vicarious trauma: a validational study. J Trauma Stress 2002;15:423-32.

10. Rudolph JM, Stamm BH, Stamm HE. Compassion fatigue: a concern for mental health policy, providers, \& administration. Annual Meeting of the International Society for Traumatic Stress Studies; Montreal, 1997.

11. Boscarino JA, Figley CR, Adams RE. Compassion fatigue following the September 11 terrorist attacks: a study of secondary trauma among New York City social workers. Int J Emerg Ment Health 2004;6:57-66.

12. Adams RE, Boscarino JA, Figley CR. Compassion fatigue and psychological distress among social workers: a validation study. Am J Orthopsychiatry 2006;76:103-8.

13. Beaton RD, Murphy $\mathrm{S}$, Johnson $\mathrm{C}$, et al. Secondary traumatic stress response in fire fighters in the aftermath of 9/11/2001. Traumatology 2004;10:7-16

14. Hooper C, Craig J, Janvrin DR, et al. Compassion satisfaction, burnout, and compassion fatigue among emergency nurses compared with nurses in other selected inpatient specialties. J Emerg Nurs 2010;36:420-7.

15. Elwood LS, Mott J, Lohr JM, et al. Secondary trauma symptoms in clinicians: a critical review of the construct, specificity, and implications for trauma-focused treatment. Clin Psychol Rev 2011;31:25-36.

16. Chen J, Bai B. Nurses mental health status and its research progress in our country. Nurs Res 2003;17:563-4.

17. Zhang WY. Measurement and analysis of firefighters' mental health status. Chin J Health Psychol 2006;14:689-90.

18. Dan $\mathrm{H}$, Wang $\mathrm{JH}$. Analysis of mental health status of grass-roots level firefighters. Mod Bus Trade Industry 2009;4:139-40.

19. Prati G, Pietrantoni L. An application of the social support deterioration deterrence model to rescue workers. J Community Psychol 2010;38:901-17.

20. Adams RE, Figley CR, Boscarino JA. The Compassion Fatigue Scale: its use with social workers following urban disaster. Res Soc Work Pract 2008;18:238-50.

21. Sun $\mathrm{BH}$, Jiang YR, Lou BN, et al. The mechanism of compassion fatigue among medical staffs: the mediated moderation model. Psychol Res 2014;7:59-66.

22. Prince-Embury S. The Ego-Resiliency Scale by Block and Kremen (1996) and Trait Ego-Resiliency. In: Prince-Embury S, Saklofske DH, eds. Resilience in children, adolescents, and adults. New York: Springer, 2012:135-8.

23. Block J, Kremen AM. IQ and ego-resiliency: conceptual and empirical connections and separateness. J Pers Soc Psychol 1996;70:349-61.

24. Li YX, Zhang $L$. The mental health of nurses: analysis based on journal of Chinese nursing document. J Henan Univ 2009;28:84-7.

25. Xiao SY. The theoretical basis and application of social support questionnaire. J Clin Psychol Med 1994;4:98-100.

26. Acock $A C$. Working with missing values. J Marriage Fam 2005;67:1012-28.

27. Schafer JL, Graham JW. Missing data: our view of the state of the art. Psychol Methods 2002;7:147-77.

28. Hu LT, Bentler PM. Fit indices in covariance structure modeling: sensitivity to underparameterized model misspecification. Psychol Methods 1998;3:424-53.

29. Bentler PM, Bonett DG. Significance tests and goodness of fit in the analysis of covariance structures. Psychol Bull 1980;88:588-606.

30. Badger K, Royse D, Craig C. Hospital social workers and indirect trauma exposure: an exploratory study of contributing factors. Health Soc Work 2008;33:63-71.

31. Yoder EA. Compassion fatigue in nurses. Appl Nurs Res 2010;23:191-7. 